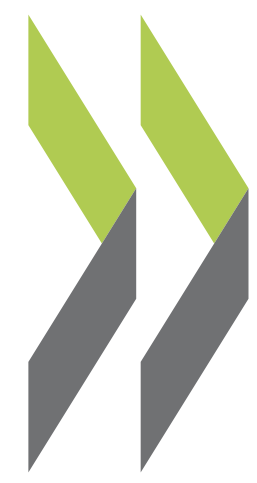

PEB Exchange, Programme on Educational Building 2005/01

\title{
ICT and Educational Property Management
}

\section{Gilbert Desmarais}

https://dx.doi.org/10.1787/578307422564 


\section{ICT AND \\ EDUCATIONAL PROPERTY MANAGEMENT}

An international PEB seminar on "Information and Communications Technology and Educational Property Management" was held in Montreal, Canada, from 31 October to 3 November 2004. The aim of this seminar was to examine how information and communications technology (ICT) can be incorporated into educational property management by investigating three issues: how ICT can make educational spaces more functional and comfortable in a sustainable development perspective, how it can improve the security and protection of facilities and, lastly, how it can optimise their technical and administrative management. The participants had the opportunity to see the theories presented in each field illustrated concretely by visiting innovative institutions in Montreal and its suburbs. A brief summary of these visits is provided below.

Faced with a situation in which most school buildings are reaching the end of their initial life cycle and financial and human resources have been reduced, educational property managers in OECD countries now more than ever before have to optimise their operating and investment strategies. Making ICT an integral part of these strategies in response to changing "modes of knowledge and flexible delivery" ${ }^{1}$ and to changing modes of educational property management is a major challenge.

In March 2003, a seminar of the OECD Programme on Educational Building (PEB) was held in Brisbane, Australia, under the theme "Bricks, Clicks and Spondulicks". In his report on this seminar, Kenn Fisher said: "On the international scene, it is clear that there is a wish for more comparative studies on educational buildings and the role of ICT in education". It followed logically that there was a need to focus on how information and communications technology could be incorporated into educational property management.

1. PEB Exchange, no. 50, October 2003, "Bricks, Clicks and Spondulicks".

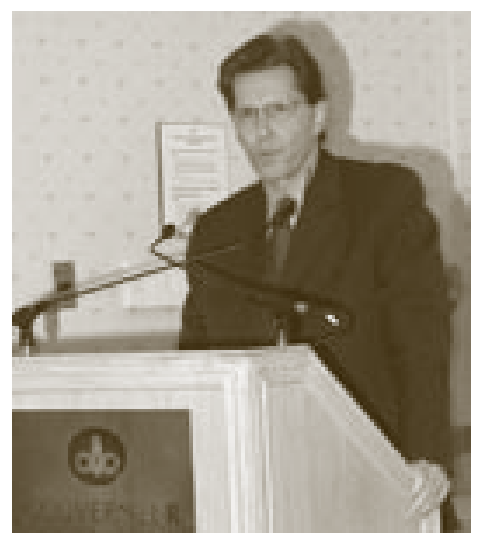

Bernard Hugonnier, Deputy Director for Education at the OECD, opening the seminar

Consequently, PEB and the Association of Institutional Property Managers (AGPI - Quebec), with the participation of the Quebec Ministry of Education and the Quebec Energy Efficiency Agency (AEE - Quebec), worked together to organise a seminar on this issue.

The Montreal seminar examined how various countries have incorporated ICT into educational property management at the national and local levels over the past ten years and reviewed the solutions that these tools can provide today. The various international experts and PEB members attending the event shared viewpoints based on experience in their own countries and institutions and discussed some of their concerns. The participants considered best practices and their impact on the educational environment, as well as the drawbacks, constraints and limitations encountered.

The discussions also offered a prospective review of how ICT might be developed to anticipate needs in the light of on-going research, current developments, trends and the emergence of new standards.

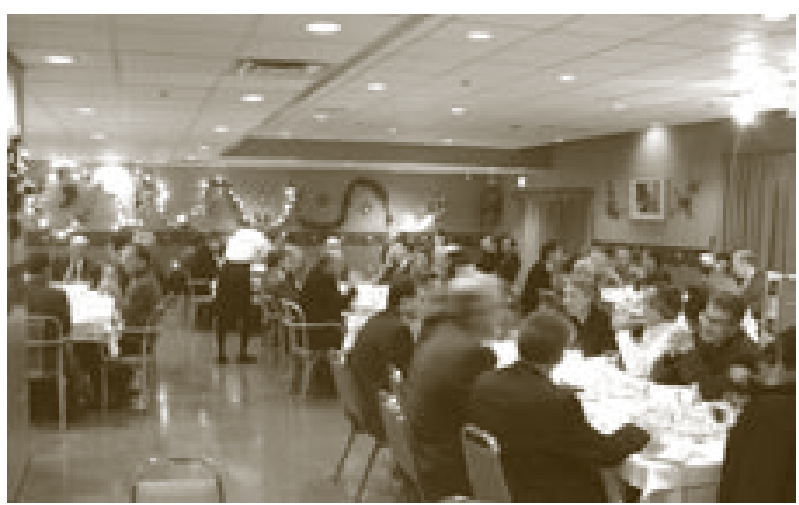

The gala dinner served by students in the food and catering programme of the Calixa-Lavallée Centre, a vocational school in Quebec 


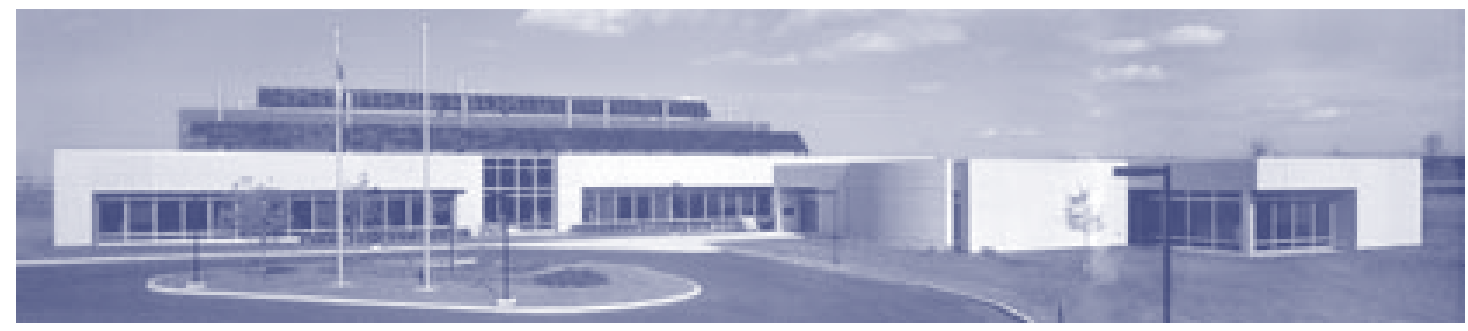

CANMET Energy Technology Centre - Varennes

A report on the seminar is currently being prepared and will be published.

\section{Technical visits}

The Université du Québec à Montréal (University of Quebec at Montreal, UQAM) is a pioneer in new technologies. It was the first university in Canada to equip its libraries with computerised catalogues. It continues to take the lead, having recently installed a "converged" telecommunications network integrating voice, data and video that now links the 45000 users of the university.

At the École de Technologie Supérieure (Superior School of Technology, ETS), participants saw how managers have succeeded in combining perfectly two generations of building management systems (remote management) by connecting the most advanced versions of centralised control systems to existing versions.

The Centre de la Technologie de l'Énergie de CANMET - Varennes (CANMET Energy Technology Centre, CTECVarennes) is one of the three energy research and innovation centres of Natural Resources Canada (RNCan). This centre's mission is to enable targeted sectors of the Canadian economy to reduce their greenhouse gas emissions, promote sustainable energy use and improve their innovation capacity. Intelligent building technologies, re-commissioning practices, photovoltaics, innovative refrigeration and the Renewable Energy Decision Support Centre are some of the many activities developed by the CTEC-Varennes.

The École du Tournant (Le Tournant School) is exceptional in terms of its design, energy performance and environmental quality. The school's designers succeeded in reducing its energy consumption to only $20.8 \%$ of the annual consumption of a typical school built in line with the requirements of the Model National Energy Code for Buildings. In addition, it has been designed so as to generate virtually no greenhouse gas. This makes it the most energy-efficient school in Quebec, and it ranked second among the buildings that participated in the Canadawide Commercial Building Incentive Programme.
The "concept-based" building of the Centre de Formation des Nouvelles Technologies de Sainte-Thérèse (New Technologies Training Centre, CFNT) supports educational activities supervised by a dynamic and innovative team. The layout recommended in its design contributes to pupils' success. This architectural and technical approach shows how information technologies can be used to promote learning in a building that combines state-of-the-art technology and openness to its surroundings with forward-looking contemporary architecture.

At the École des Hautes Études Commerciales (School for Advanced Commercial Studies, HEC), a cable network was designed to serve 6000 portable computers. This cable network has 10000 connections and the same number of electrical outlets enabling students and teachers to use the computer network in classes or virtually anywhere in the building in order to study or participate in group work. The network has been made secure using the latest technologies available in this field.

Concordia University has equipped over $80 \%$ of its educational areas with wireless technologies. Its wireless network has 150 access points, each with a range of over 600 meters. This institution has incorporated multimedia functions and Internet connections into a wide range of multi-purpose spaces. This enables each user to have network access without being confined to a single designated area.

The Organising Committee wishes to thank all the partners and contributors who helped to make an event of this scale a "great success in all respects", including everyone who contributed to the success of the technical visits.

Article contributed by the Organising Committee.

For more information, contact:

Gilbert Desmarais

AGPI, Quebec, Canada

Tel.: 15147475961

E-mail: secretariat@agpi.org 